Research Article

\title{
Research and Application of a Reinforced Concrete Simplified Model
}

\author{
Haipeng Jia $\mathbb{D i D}^{1,2}$ and Shuaikang Tian $\mathbb{D i D}^{1}$ \\ ${ }^{1}$ School of Mechanics and Civil Engineering, China University of Mining and Technology (Beijing), Beijing 100083, China \\ ${ }^{2}$ School of Civil Engineering, Luoyang Institute of Science and Technology, Luoyang 471023, China \\ Correspondence should be addressed to Haipeng Jia; bqt1700603024@student.cumtb.edu.cn
}

Received 10 September 2020; Revised 30 January 2021; Accepted 9 February 2021; Published 22 February 2021

Academic Editor: Melina Bosco

Copyright (c) 2021 Haipeng Jia and Shuaikang Tian. This is an open access article distributed under the Creative Commons Attribution License, which permits unrestricted use, distribution, and reproduction in any medium, provided the original work is properly cited.

\begin{abstract}
To accurately and efficiently carry out numerical calculations for blasting demolition projects, based on the basic principles of engineering mechanics, a simplified concrete model is established. This model represents the postpeak behavior of concrete in compression and the peak behavior in traction. Based on the mechanical properties of steel and concrete materials, a new reinforced concrete model is proposed. The proposed reinforced concrete model has been implemented in the computer program LS-DYNA and used to simulate a real blasting demolition. The result shows that this model can accurately reflect the collapse and movement process of the chimney.
\end{abstract}

\section{Introduction}

In current engineering applications, concrete is considered to be in a safe state only when its peak strength is not exceeded. In the field of blasting demolition, the process of blasting demolition is accompanied by the failure of materials. The failure process of materials is related to their postpeak mechanical properties, and it is necessary to study the mechanical characteristics of concrete materials on the postpeak stage. Especially for demolition blasting, this postpeak characteristic determines whether the lower seat of demolition blasting occurs.

Furthermore, for blasting simulation modeling, a simple reinforced concrete material which can represent the overall behavior of concrete and rebar is often preferred due to its computational efficiency.

Wei and Yong [1] proposed a tensile constitutive model of reinforced concrete based on the existing continuous damage theory. Bifeng and Junjie [2] introduced the influence of steel bars based on the concrete microplane model and proposed a reinforced concrete dynamic constitutive model. Lin et al. [3] constructed a dynamic damage constitutive model of reinforced concrete based on its viscoelastic properties. Xinjin et al. [4] adopted the assumption of strain coordination and strength equivalence [5] and gave a constitutive model describing the damage of reinforced concrete materials, and they observed that after the reinforcement yielded, the material strength immediately entered the decline stage but did not consider the tension stiffening effect and compression stirrup restraint effect caused by the interaction of the concrete and reinforcement. Chao et al. [6] used the principle of stiffness equivalence to treat reinforced concrete as a continuous homogeneous material and simplified the constitutive relationship of reinforced concrete materials by using the piecewise linear method. He further modified the tensile stiffness effect caused by the interaction of reinforcement and concrete but did not consider the restraint effect of stirrups and the influence of reinforcement ratio on the tensile stiffness effect. At present, in the field of demolition blasting, the research on the mechanical properties of concrete mainly focuses on the prepeak stage of the material, and there is little research on the mechanical properties of the postpeak stage of the material. To perform more accurate numerical calculations for demolition blasting projects, these postpeak characteristics must be studied. 
Commonly, the representation of a reinforced concrete element requires separate material models for concrete and steel and a proper mesh discretization. The need for a dense discretization grid could have a detrimental effect on calculation efficiency; moreover, the traditional finite element algorithm often forces the calculation to be terminated. In the finite element software LS-DYNA, this happens because existing materials are not able to reflect the large deformation of the postpeak response of concrete. In the numerical calculation of demolition blasting, the *MAT_JOHNSON_HOLMQUIST_CONCRETE model and ${ }^{*}$ MAT_RHT model [7] are often used to calculate the mechanical properties of concrete materials. However, the HJC model uses a unified strain rate effect enhancement factor, which cannot accurately reflect the tensile and compressive strain rate effects of materials; although the RHT model can reflect material strain rate effects and less obvious postpeak softening effect, it cannot accurately reflect the softening characteristics of the material after the peak in the demolition blasting.

In this paper, the authors focus on the tensile and compressive behavior of concrete and steel with special attention to the postpeak behavior of concrete. Based on this knowledge, the envelope curve of a reinforced concrete material is proposed and used to set a predefined material in the computer program LS-DYNA.

\section{Study on the Mechanical Properties of Concrete}

2.1. Simplified Mechanical Properties of Concrete Materials Subjected to Axial Tensile Stress. The study of the mechanical properties of concrete materials in the prepeak stage needs to meet three conditions:

(1) The material is uniform. (2)In the experimental, the material is in a state of uniform stress and uniform strain at all times. (3) The size of the specimen does not change much in the experimental.

After applying axial tension to the specimen, corresponding stress and deformation are generated in the concrete material. When the deformation exceeds a certain degree, microfractures begin to occur in the specimen and the occurrence of these microfractures is random. The presence of these microfractures is represented by the damage variable $D$.

Assume that the original cross-sectional area of the specimen is $\mathrm{A}$, and the effective cross-sectional area after the damage is $A_{i}$. Then, the damage on the section of the material can be expressed as follows:

$$
D=1-\frac{A_{i}}{A} .
$$

In the equation, $D$ is the damage variable, and its value range is $[0,1]$. When $D=0$, the material is not damaged, when $D=1$, the material is destroyed; $A_{i}$ is the effective area of the material.

The nominal stress on the cross section of the concrete material based on the above three assumptions can be expressed as the following equation:

$$
\sigma=\frac{F}{A} .
$$

The true stress on the cross section of the material can be expressed as the following equation:

$$
\sigma_{i}=\frac{F}{A_{i}} .
$$

Then, the relationship between nominal stress and real stress can be obtained by equations (1)-(3) and it can be expressed as the following equation:

$$
\sigma_{i}=\frac{\sigma}{(1-D)} .
$$

In the equation, $\sigma$ is the nominal stress, $\sigma_{i}$ is the real stress, and $D$ is the damage variable, and it can be calculated according to the expression in the Chinese Code for the design of concrete structures (GB 50010-2010) [8].

The damage variable has a clear physical meaning, but the true effective area of material under uniaxial action is difficult to accurately determine. The equivalent strain hypothesis holds that the strain produced by the nominal stress acting on the damaged material is equivalent to the strain produced by the effective stress acting on the nondamaged specimen. Therefore, either by replacing the nominal stress in the nondamaged specimen with the effective stress after damage or replacing the elastic modulus of the nondamaged specimen with the effective elastic modulus of the damaged material, the constitutive equation of the damaged material can be obtained and expressed as the following equation:

$$
\varepsilon=\frac{\sigma_{i}}{E}=\frac{\sigma}{E(1-D)}=\frac{\sigma}{E_{i}} .
$$

In the equation, $E$ is the elastic modulus of the nondamaged specimen and $E_{i}$ is the elastic modulus of the damaged material.

The constitutive relationship when the size of the concrete material does not change under uniaxial action can be expressed as the following equation:

$$
\sigma=E(1-D) \varepsilon .
$$

Equation (6) is derived based on the above three assumptions. It has the same form as the concrete constitutive expression in the Chinese Code for the design of concrete structures (GB 50010-2010).

Under the action of axial tensile stress, concrete materials can withstand little deformation and exhibit brittle characteristics. Before reaching the peak tensile strength of the concrete material, its stress-strain relationship can be expressed by equation (6). It is assumed that under the action of axial tensile tension, when the strain at peak stress is exceeded, the postpeak stress directly becomes 0 .

The mechanical properties of the concrete material under axial tension can be expressed as the following equation:

$$
\begin{cases}\sigma_{t}=E(1-D) \mathcal{\varepsilon}, & \varepsilon \leq \varepsilon_{0}, \\ \sigma_{t}=0, & \varepsilon>\varepsilon_{0} .\end{cases}
$$


Under axial tension, the simplified mechanical properties of concrete materials are shown in Figure 1.

\subsection{Optimization of Mechanical Properties of Concrete Ma-} terials under Axial Compression. Compared with the axial tensile mechanical properties, concrete materials can withstand greater loads and deformations under axial compression. With the continuous increase of the axial pressure of the concrete material, the internal damage of the material continues to increase simultaneously. When the deformation exceeds the strain at peak stress, the microfractures begin to expand and the material enters the postpeak state, which is characterized by a significant deformation of the material until it fails macroscopically. In the finite element calculation, it often happens that if the deformation of the material is too large, the calculation is forced to terminate. In this case, under the conditions of uniform material and uniform stress and strain, it is necessary to further study the mechanical properties of concrete material for large postpeak deformations in compression.

In general, the initial state of strain-softening reflects the transformation of the material from a continuum to a structure and the change in the geometric size of the material. The study of the mechanical properties of concrete materials under axial compression needs to meet the following three assumptions: (1)the material is uniform; (2)in the experimental, the material is in a state of uniform stress and uniform strain at all times; (3) the size of the specimen occurs a macroscopic change in the test.

Under the action of axial compression, the size of the material changes greatly; especially in the postpeak stage, the size of the concrete material changes significantly and is accompanied by the destruction of the material. Therefore, under axial compression, the longitudinal microstrain of the concrete material can be expressed as the following equation:

$$
\mathrm{d} \varepsilon=\frac{\mathrm{d} L}{L_{i}} .
$$

In the equation, $L_{i}$ is the current length of the concrete material. Integrating the $L_{i}$, the true axial strain of the concrete material can be obtained as the following equation:

$$
\varepsilon_{i}=\int_{L_{0}}^{L_{i}} \frac{\mathrm{d} L}{L_{i}},
$$

where $L_{0}$ is the initial length of the concrete material.

Equation (9) reflects the superposition of concrete material deformation at any time, which can accurately represent the real deformation of concrete materials under axial compression and reflect the softening behavior characteristics of concrete materials.

To accurately study the softening behavior characteristics of concrete materials under compression, the influence of the change of the material section due to the Poisson effect cannot be ignored. According to the conservation of volume, it can be written as follows:

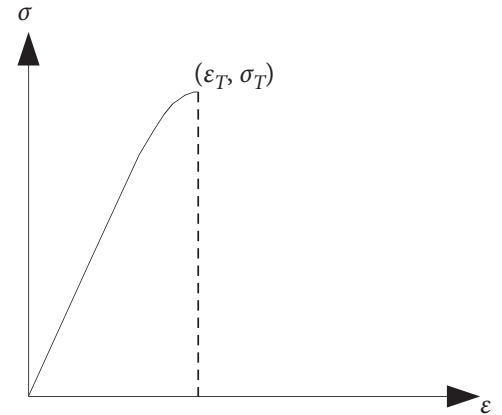

FIGURE 1: Simplified mechanical properties of concrete under uniaxial tension.

$$
L_{0} A_{0}=L_{i} A_{i}
$$

where $A_{0}$ is the initial cross-sectional area of the concrete material, $L_{0}$ is the initial length of the concrete material, $A_{i}$ is the uniaxial compression cross-sectional area of the concrete material at any time, and $L_{i}$ is the length of the concrete material at any time.

Then, when the concrete material undergoes softening behavior under axial compression, its stress-strain relationship can be expressed as the following equation:

$$
\sigma_{i}=\sigma\left(\frac{L_{i}}{L_{0}}\right) .
$$

From equations (9) and (11), the true stress of concrete material under axial compression can be expressed as the following equation:

$$
\sigma_{i}=\sigma \cdot e^{\varepsilon_{i}} .
$$

The nominal strain of concrete material under axial compression can be expressed as the following equation:

$$
\varepsilon=\frac{L}{L_{0}}-1
$$

From equations (9) and (13), the true strain of concrete material under axial compression can be obtained as the following equation:

$$
\varepsilon_{i}=\ln (1+\varepsilon) .
$$

Combining equations (6)-(12) and (14), the envelope curve of concrete under axial compression can be expressed with the following equation:

$$
\sigma_{c}=E(1-D) e^{\varepsilon_{i}}\left(e^{\varepsilon_{i}}-1\right) .
$$

The optimized envelope curve of concrete materials under compression is shown in Figure 2.

Equation (15) considers the superposition of concrete material strain at any time and considers the change of material shape due to the Poisson effect under compression. It can be applied to the study of the mechanical characteristics of concrete material in the postpeak deformation. 


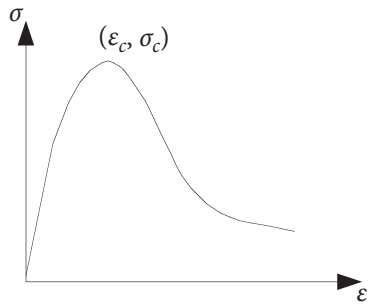

Figure 2: Optimized postpeak mechanical properties of concrete under uniaxial compression.

\section{Constitutive Model of Concrete Confined by Stirrups}

The stirrups have a strengthening effect on the volume of concrete enclosed by the "cage" constituted by the longitudinal reinforcements and the stirrups themselves. Based on the Mander confinement model, the strengthening effect of the stirrups on the concrete is accounted for in the proposed material model as an increase in strength and ductility of the material.

The Mander confined concrete constitutive model [9] was proposed by Mander in 1988, and in his paper, the enveloper curve of concrete proposed by Popovics is adopted, which is suitable for the representation of concrete strength under low strain rate and cyclic loading. The shape of the envelope curve is shown in Figure 3 for two different confinement conditions.

The full stress-strain curve of the concrete in the confinement zone can be expressed as the following equation:

$$
\frac{\sigma}{\sigma_{c c}}=\frac{r \cdot x}{r-1+x^{r}}
$$

where $\sigma_{c c}$ is the peak stress of confined concrete and $\sigma$ is the stress of confined concrete.

Define $x$ as the ratio of confined concrete longitudinal compressive strain to peak compressive strain, and it can be expressed as the following equation:

$$
x=\frac{\varepsilon}{\varepsilon_{c c}} .
$$

In the equation, $\varepsilon$ is the longitudinal compressive strain of confined concrete and $\varepsilon_{c c}$ is the peak compressive strain of confined concrete.

The correlation coefficient of concrete brittleness $r$ is defined, and it is given by the following equation:

$$
r=\frac{E_{c}}{E_{c}-E_{\mathrm{sec}}}
$$

where $E_{c}$ is the initial elastic modulus of concrete and $E_{\mathrm{sec}}$ is the secant modulus of constrained concrete.

The longitudinal peak compressive strain of confined concrete can be expressed as the following equation:

$$
\varepsilon_{c c}=\varepsilon_{c 0}\left[1+5\left(\frac{\sigma_{c c}}{\sigma_{c}}-1\right)\right] .
$$

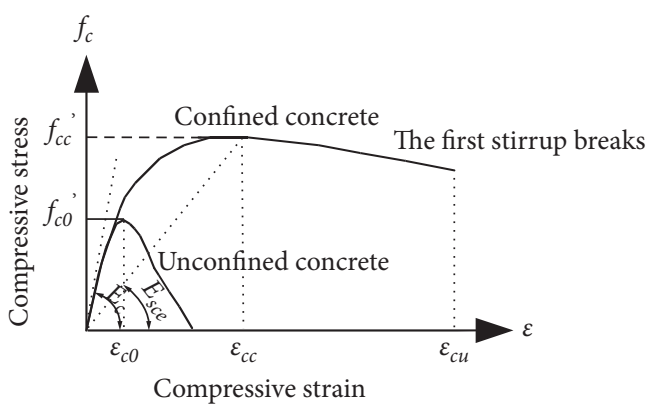

FIgURE 3: Envelope curve of Mander's confinement model.

In the equation, $\sigma_{c c}$ is the peak strength of confined concrete, $\sigma_{c}$ is the peak strength of unconfined concrete, and $\varepsilon_{c o}$ is the strain at peak stress of unconfined concrete.

The strain of confined concrete when the stirrup breaks can be expressed as the following equation:

$$
\varepsilon_{c u}=0.004+1.4 \varepsilon_{s u} \rho^{\prime} \frac{\sigma_{y}^{\prime}}{\sigma_{c c}},
$$

where $\varepsilon_{c u}$ is the confined concrete strain when the stirrup breaks, $\rho$ ' is the volume reinforcement ratio of the stirrup, $\sigma_{y}$, is the yield strength of the stirrup, and $\varepsilon_{s u}$ is the ultimate strain of the constrained stirrup.

\section{A New Simplified Model of Reinforced Concrete}

4.1. Steel Modeling. In this study, the constitutive behavior of reinforcing steel is represented by the elastic-perfectly plastic law represented in Figure 4:

$$
\sigma_{s}= \begin{cases}E_{s} \varepsilon_{s}, & 0 \leq \varepsilon_{s} \leq \varepsilon_{y}, \\ f_{y}, & \varepsilon_{y} \leq \varepsilon_{s} \leq \varepsilon_{s, h} .\end{cases}
$$

4.2. Calculation of Equivalent Elastic Modulus and Equivalent Stress. In the axial compression analysis, the stirrups have a strengthening effect on the confined concrete. To simplify the modeling workload, the strengthening effect of stirrups on the concrete can be represented by the increase in concrete strength. Assume that the section size of the reinforced concrete element is $b \times h$, and the area of the longitudinal reinforcement is $n \times A_{i}$.

The longitudinal reinforcement ratio can be calculated with the following equation:

$$
\rho=\frac{n \cdot A_{i}}{b \cdot h}
$$

In the equation, $\rho$ is the longitudinal reinforcement ratio, $n$ is the number of longitudinal bars, $A_{i}$ is the sectional area of a single longitudinal bar, $b$ is the section width, and $h$ is the section length.

The concrete area can be expressed as the following equation:

$$
A_{c}=b h-n A_{i}
$$




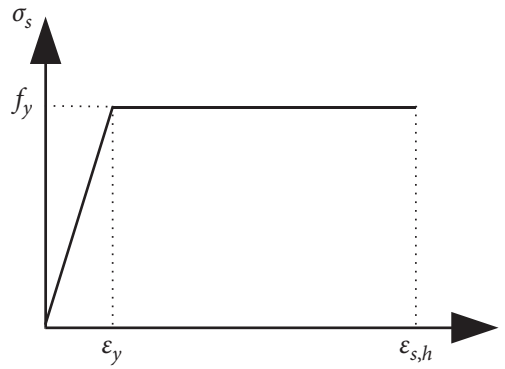

FIGURE 4: Schematic diagram of the bilinear law adopted to model the reinforcement.

Under the action of the axial force, provided that the strain in the reinforcements and the concrete is the same, according to the force balance condition, it is

$$
E_{\mathrm{eq}} \cdot \varepsilon \cdot A=n \cdot A_{i} \cdot E_{s} \cdot \varepsilon_{s}+E_{c} \cdot \varepsilon_{c} \cdot A_{c} .
$$

From equations (23) and (24), it can be found that when the strains of reinforcement and concrete are equal, the equivalent elastic modulus of reinforced concrete can be expressed as the following equation:

$$
E_{\mathrm{eq}}=E_{s} \cdot \rho+E_{c}(1-\rho),
$$

where $E_{\mathrm{eq}}$ is the equivalent elastic modulus of reinforced concrete, $E_{s}$ is the elastic modulus of reinforcement, $E_{c}$ is the elastic modulus of concrete, and $\rho$ is the longitudinal reinforcement ratio.

The equivalent stress of the reinforced concrete material can be expressed with the following equation:

$$
\sigma_{\mathrm{eq}}=(1-\rho) \sigma_{c}+\rho \sigma_{s},
$$

where $\sigma_{\text {eq }}$ is the equivalent stress of reinforced concrete, $\sigma_{c}$ is the stress of concrete, and $\sigma_{s}$ is the stress of reinforcement.

\subsection{Mechanical Properties of Reinforced Concrete Subjected to} Axial Tensile Stress. The tensile mechanical properties of concrete materials are shown in Figure 1, and it is shown in equation (7). Before the strain at peak stress of concrete, the deformation of both reinforcement and concrete is small. It is considered that both reinforcement and concrete are in the elastic stage, and the strains of reinforcement and concrete are equal. Then, the tensile mechanical properties of reinforced concrete at the strain at peak stress of concrete can be expressed as the following equation:

$$
\sigma_{t, 1}=E_{t, \mathrm{eq}} \cdot \varepsilon_{t, 1},
$$

where $\sigma_{t, 1}$ is the peak tensile stress of reinforced concrete materials under axial tension and $\varepsilon_{t, 1}$ is the peak tensile strain of reinforced concrete materials (it equals the peak tensile strain of concrete). $E_{t, \text { eq }}$ is the equivalent elastic modulus of reinforced concrete under tension.

When the concrete strain exceeds its strain at peak stress, it begins to enter the softening stage, which can be regarded as the concrete material failure under tensile tension. After that, the axial tensile tension is sustained entirely by the longitudinal reinforcement, and then the reinforcement enters the yielding state. At this time, the mechanical properties of reinforced concrete can be expressed as the following equations:

$$
\begin{aligned}
\sigma_{t, 2} & =\sigma_{s, 2} \cdot \rho, \\
\varepsilon_{t, 2} & =\varepsilon_{y},
\end{aligned}
$$

where $\sigma_{t, 2}$ is the brittle rupture stress of reinforced concrete materials under axial tension and $\varepsilon_{t, 2}$ is the ultimate tensile strain of reinforced concrete under axial tension. $\sigma_{s, 2}$ is the yield stress of the reinforcement under axial tension; $\varepsilon_{y}$ is the yield strain of the reinforcement under axial tension.

After the reinforcement enters the yield stage, necking begins to occur. To simplify the calculation, it is considered that tensile fracture occurs when the reinforcement reaches the yield strength. At this time, the reinforced concrete material can be truncated by tensile stress. The mechanical model of reinforced concrete material under axial tension can be expressed in Figure 5.

\subsection{Simplified Mechanical Properties of Reinforced Concrete} under Axial Compression. When the reinforced concrete material is subjected to axial pressure, the stirrups have a restraint strengthening effect on concrete. This effect can be expressed by the confinement model illustrated in the second section. The material is compressed and deformed under the action of axial pressure, from the beginning until it is broken. It is assumed that plane sections remain plane, the strain at each position on the section is equal, a perfect bond exists between concrete and reinforcement, and no external bulging phenomenon occurs. The strain of reinforced concrete material under axial compression can be expressed as the following equation:

$$
\varepsilon=\varepsilon_{s}=\varepsilon_{c},
$$

where $\varepsilon_{\mathcal{s}}$ is the compressive strain of reinforcement under axial compression and $\varepsilon_{c}$ is the compressive strain of concrete under axial compression.

When both reinforcement and concrete are in the elastic deformation stage, the mechanical properties of reinforced concrete material under axial compression can be expressed as the following equation:

$$
\sigma_{c, 1}=E_{c, \text { eq }} \cdot \varepsilon_{c, 1},
$$

where $\sigma_{c, 1}$ is the elastic limit stress of reinforced concrete material under axial compression, $E_{c \text {, eq }}$ is the equivalent elastic modulus of reinforced concrete material under axial compression, and $\varepsilon_{c, 1}$ is the elastic compressive strain of concrete confined by stirrups.

When the confined concrete material begins to undergo plastic deformation under axial compression, although the stress continues to increase, its rate of increase gradually decreases, but the reinforcement is still in the elastic stage, and the proportion of pressure carried by the reinforcement gradually increases. When the confined concrete reaches its strain at peak stress, to simplify the calculation, it is considered that the reinforcement also enters the yield state; at 


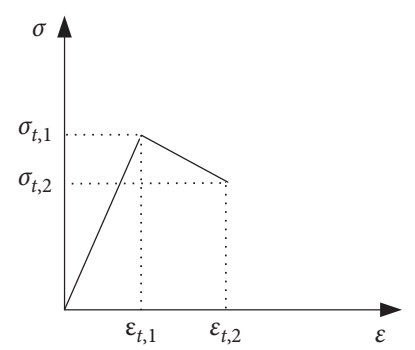

Figure 5: Schematic diagram of the mechanical properties of reinforced concrete materials under axial tension.

this time, the peak stress of reinforced concrete material can be expressed as the following equation:

$$
\sigma_{c, 2}=(1-\rho) \sigma_{s c, 2}+\rho \sigma_{s, 2},
$$

where $\sigma_{c, 2}$ is the peak stress of reinforced concrete material under axial compression, $\sigma_{s c, 2}$ is the peak stress of confined concrete, which can be calculated according to equation (16), $\sigma_{s, 2}$ is the yield stress of longitudinal reinforcement under axial compression, and $\rho$ is the longitudinal reinforcement ratio.

At this time, the strain at peak stress of reinforced concrete material under axial compression can be calculated by equation (19).

After the longitudinal reinforcement yields, its stress remains unchanged. Due to the restraint of the stirrups, the postpeak ductility characteristics of concrete are remarkable. When the stirrup fracture occurs, it is regarded as the reinforced concrete material compression failure. The mechanical properties of reinforced concrete materials under axial compression can be expressed as the following equations:

$$
\sigma_{c, 3}=(1-\rho) \sigma_{s c, 3}+\rho \sigma_{s, 2},
$$

where $\sigma_{c, 3}$ is the failure stress of reinforced concrete materials under axial compression, $\varepsilon_{c, 3}$ is the failure strain of reinforced concrete materials under axial compression, and $\sigma_{s, 3}$ and $\rho$ are the yield strength and reinforcement ratio of longitudinal reinforcement, respectively.

The failure strain of reinforced concrete materials under axial compression can be calculated by equation (20).

The stress-strain law of the proposed uniaxial reinforced concrete material under compression is shown in Figure 6.

\section{Model Parameter Determination and Verification}

The analytical application of this study is based on the computer software LS-DYNA, which is an explicit dynamic analysis program, based on the Lagrange algorithm, combined with ALE and Euler algorithm. Its explicit algorithm can simulate the large displacement deformation problem. The proposed envelope curve for reinforced concrete has been implemented in LS-DYNA. The implementation consisted in editing the material template MAT_PLASTICITY_COMPRESSION_TENSION [7]. This material template allows the user to assign the envelope curve for a

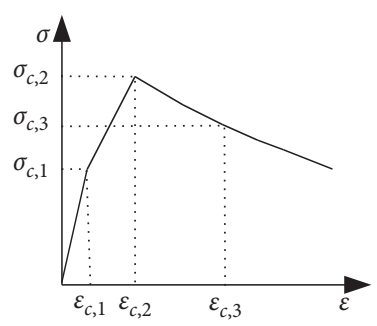

FIgURE 6: Schematic diagram of mechanical properties of reinforced concrete materials under axial compression.

custom material for both tensile and compressive stress. The other parameters required to define the material are density (RO), elastic modulus (E), Poisson's ratio (PR), material failure parameter (FAIL), custom curve LCSRT and LCSRC, custom curve LCIDT, and LCIDC. LCSRT and LCSRC define a unique strain rate custom curve for tension and compression, and LCIDT and LCIDC define unique yield stress versus effective plastic strain for tension and compression.

The simulation of a tensile and compression test is performed in LS-DYNA on a simple reinforced concrete prismatic element, similar in shape to a C30 standard specimen, to obtain the stress-strain response of the proposed material. The parameter values are shown in Table 1, and the complete stress-strain curve is shown in Figure 7. It accurately reproduces the postcompressive mechanical properties of concrete reflected in equation (15) and the tensile stress truncation characteristics reflected in equation (7).

5.1. Axial Compression Experimental Verification of the Reinforced Concrete Simplified Model. In this section, the proposed material model is validated by comparing the force deformation response of actual reinforced concrete specimens with the ones obtained numerically. Details about the tests on the real specimens could be found in $[10,11]$. Geometrical dimensions of reinforced concrete axially compressed short columns: length is $150 \mathrm{~mm}$; width is $150 \mathrm{~mm}$; height is $450 \mathrm{~mm}$; concrete compressive strength $f c=58.6 \mathrm{MPa}$; longitudinal reinforcement yield strength is $530 \mathrm{MPa}$, and longitudinal reinforcement ratio is $0.84 \%$; the protective layer thickness is $25 \mathrm{~mm}$; stirrup strength grade is HPB235, with the stirrup ratio is $0.82 \%$, and the hoop characteristic value is 0.03 . The axial loading rate is $10 \mathrm{~mm} / \mathrm{s}$. In the finite element calculation of the axial compression short column, the concrete adopts the simplified model, and the Solid164 element is used to build the model. Both the upper and lower plates adopt rigid models, the lower plate is fully constrained, and the upper plate can only move in the longitudinal direction. By loading the upper plate, the centroids of the plate block and the column are kept on the same axis. Automatic single-sided contact between the plate and the column is adopted. The stressstrain point of the envelope curve of the simplified model is shown in Table 2, and the finite element model is shown in Figure 8. 
TABLE 1: The parameter values of the C30 standard cube element.

\begin{tabular}{|c|c|c|c|c|c|c|c|}
\hline \multirow{3}{*}{$\begin{array}{l}\mathrm{RO} \\
2500 \mathrm{~kg} / \mathrm{m}^{3} \\
\text { LCIDC } \\
\end{array}$} & & \multicolumn{2}{|c|}{$\mathrm{E}$} & \multicolumn{2}{|c|}{$\mathrm{PR}$} & \multicolumn{2}{|c|}{ FAIL } \\
\hline & & \multicolumn{2}{|c|}{$30 \mathrm{GPa}$} & \multicolumn{2}{|c|}{0.255} & \multicolumn{2}{|c|}{0.016} \\
\hline & & \multicolumn{2}{|c|}{ LCIDT } & \multicolumn{2}{|c|}{ LCSRT } & \multicolumn{2}{|c|}{ LCSRC } \\
\hline 0 & $1.50 \mathrm{MPa}$ & $0.00 E+00$ & $0.30 \mathrm{MPa}$ & $1 E-5$ & -1 & $1 E-5$ & 1 \\
\hline $1.02 E-06$ & $7.17 \mathrm{MPa}$ & $6.17 E-08$ & $0.90 \mathrm{MPa}$ & $1 E-4$ & -1.0874 & $1 E-4$ & 1.0382 \\
\hline $3.42 E-05$ & $18.20 \mathrm{MPa}$ & $2.14 E-07$ & $1.49 \mathrm{MPa}$ & $1 E-3$ & -1.1803 & $1 E-3$ & 1.1165 \\
\hline $1.71 E-04$ & $26.00 \mathrm{MPa}$ & $1.05 E-06$ & $2.07 \mathrm{MPa}$ & $1 E-2$ & -1.2841 & $1 E-2$ & 1.2022 \\
\hline $2.93 E-04$ & $28.40 \mathrm{MPa}$ & $2.20 E-06$ & $2.33 \mathrm{MPa}$ & $1 E-1$ & -1.3962 & $1 E-1$ & 1.2934 \\
\hline $6.37 E-04$ & $30.00 \mathrm{MPa}$ & $4.33 E-06$ & $2.57 \mathrm{MPa}$ & $1 E-0$ & -1.5219 & $1 E-0$ & 1.39 \\
\hline $2.99 E-03$ & $16.30 \mathrm{MPa}$ & $8.02 E-06$ & $2.76 \mathrm{MPa}$ & $1 E+01$ & -1.6488 & $1 E+01$ & 1.5020 \\
\hline $5.22 E-03$ & $9.21 \mathrm{MPa}$ & $1.41 E-05$ & $2.88 \mathrm{MPa}$ & & & & \\
\hline $9.34 E-03$ & $4.71 \mathrm{MPa}$ & $1.16 E-04$ & 0 & & & & \\
\hline
\end{tabular}

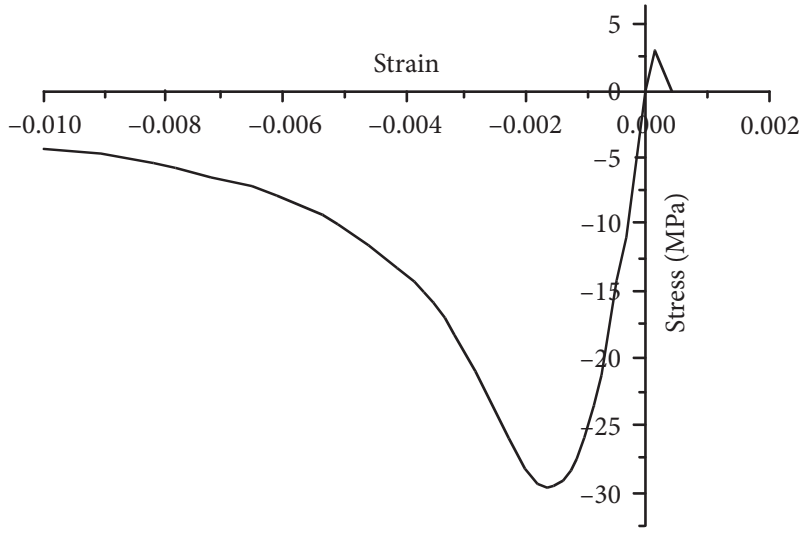

FIgURE 7: The complete stress-strain curve of C30 concrete under uniaxial action.

TABLE 2: Simplified model mechanical parameters of the reinforced concrete axially compressed short column.

\begin{tabular}{lc}
\hline Strain & Stress \\
\hline$\varepsilon_{c, 1}=1.2 \times 10^{-3}$ & $\sigma_{c, 1}=46.56 \mathrm{MPa}$ \\
$\varepsilon_{c, 2}=3.0 \times 10^{-3}$ & $\sigma_{c, 2}=68.45 \mathrm{MPa}$ \\
$\varepsilon_{c, 3}=4.0 \times 10^{-3}$ & $\sigma_{c, 3}=64.68 \mathrm{MPa}$ \\
$\varepsilon_{t, 1}=1.45 \times 10^{-4}$ & $\sigma_{t, 2}=4.72 \mathrm{MPa}$ \\
$\varepsilon_{t, 2}=2.65 \times 10^{-3}$ & $\sigma_{t, 2}=4.72 \mathrm{MPa}$ \\
\hline
\end{tabular}

Incorporating the above parameters into the numerical model, the numerical calculation result and experimental result of the load-strain curve of the simplified model can be obtained in Figure 9.

It can be seen from Figure 9 that there is a certain difference in the axial stiffness and maximum load capacity between the numerical calculation result and the experimental result. This is because the experimental material and the equivalent material have a certain difference in material uniformity. However, the overall trend of the numerical calculation result and the experimental result are consistent.

5.2. Compression and Bending Experimental Verification of the Reinforced Concrete Simply Supported Beam Simplified

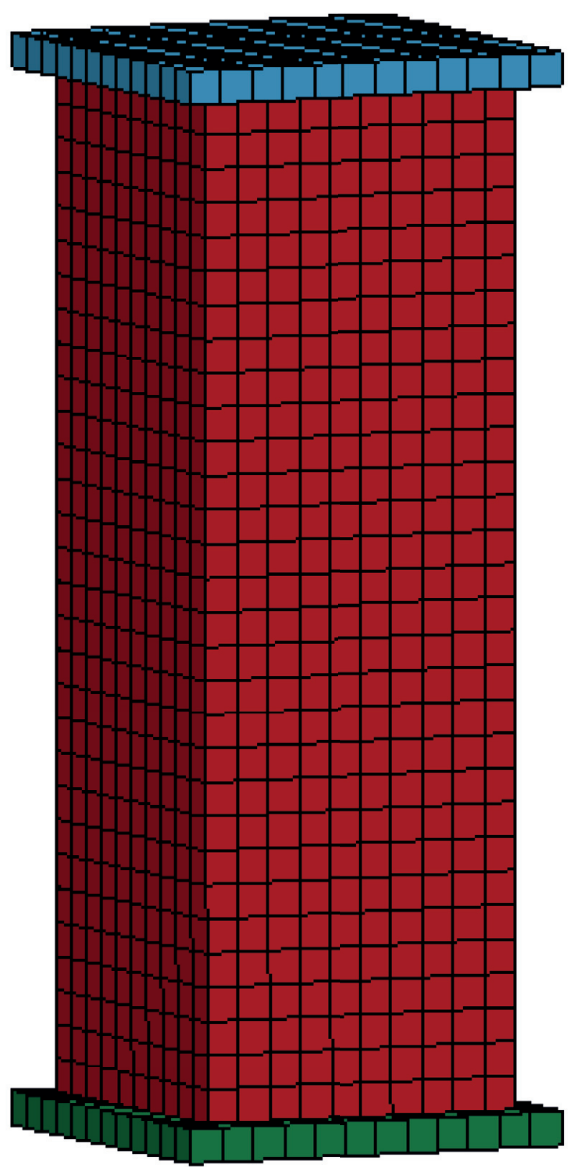

FIGURE 8: Finite element model of the reinforced concrete short columns under axial compression.

Model. The geometric dimensions of the reinforced concrete simply supported beam are as follows: length is $1400 \mathrm{~mm}$, width is $150 \mathrm{~mm}$, height is $200 \mathrm{~mm}$, and support spacing is $1200 \mathrm{~mm}$. The concrete strength grade is C25, and the protective layer thickness is $25 \mathrm{~mm}$. The longitudinal reinforcement grade is HRB335, and the reinforcement ratio is $1.05 \%$. The stirrup grade is HPB235, and the stirrup ratio is $0.628 \%$. A two-point monotonic loading method is adopted, 


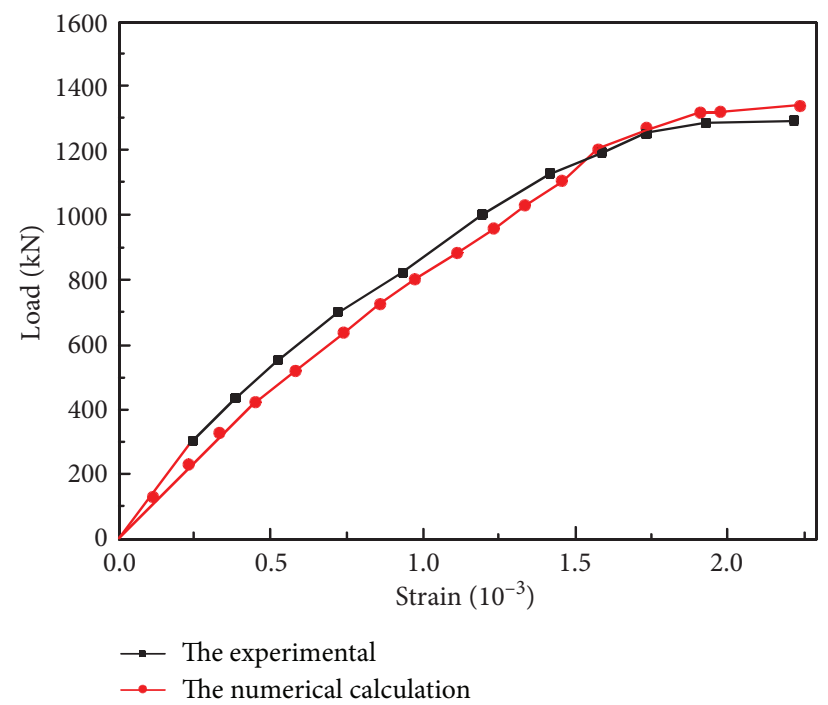

Figure 9: Comparison of the load-strain curve between numerical calculation and experimental of the reinforced concrete short column simplified model under axial compression.

and the loading rate is $10 \mathrm{~mm} / \mathrm{s}$. In the finite element calculation of the simply supported beam compression and bending test, the simply supported beam adopts the simplified model, and the Solid164 element is used to build the model. Both the loading plate and the roller adopt the rigid body model. The loading plate can move in the vertical direction and rotate in the plane. Automatic single-sided contact is adopted in the test. The mechanical parameters of the simplified model are shown in Table 3, and the finite element model is shown in Figure 10.

Incorporating the above parameters into the numerical model, the numerical calculation result and experimental result of the load-displacement curve of the reinforced concrete simply supported beam simplified model are shown in Figure 11.

The numerically calculated load-displacement curve has certain volatility after the elastic phase, but after averaging the vibration data, it can be seen from Figure 11 that the numerical calculation result can reflect the changing trend of the experimental result.

\section{Application}

In this section, the proposed reinforced concrete model is applied to simulate a real blasting demolition project. The analytical simulation is then compared to the real demolition event using high-speed photographic observation. The experimental result of chimney blasting demolition comes from the literature [12].

The height of a reinforced concrete chimney is $210 \mathrm{~m}$, its bottom outer radius is $9.97 \mathrm{~m}$, wall thickness is $600 \mathrm{~mm}$, top outer radius is $4.23 \mathrm{~m}$, wall thickness is $200 \mathrm{~mm}$, and the concrete strength grade is $\mathrm{C} 30$. The average reinforcement rate of longitudinal reinforcements is $0.50 \%$, and the average
TABle 3: Simplified model parameters of the reinforced concrete simply supported beam.

\begin{tabular}{lc}
\hline Strain & Stress \\
\hline$\varepsilon_{c, 1}=3.53 \times 10^{-4}$ & $\sigma_{c, 1}=10.10 \mathrm{MPa}$ \\
$\varepsilon_{c, 2}=2.26 \times 10^{-3}$ & $\sigma_{c, 2}=30.47 \mathrm{MPa}$ \\
$\varepsilon_{c, 3}=4.08 \times 10^{-3}$ & $\sigma_{c, 3}=28.01 \mathrm{MPa}$ \\
$\varepsilon_{t, 1}=1.09 \times 10^{-4}$ & $\sigma_{t, 1}=3.26 \mathrm{MPa}$ \\
$\varepsilon_{t, 2}=1.68 \times 10^{-3}$ & $\sigma_{t, 2}=3.51 \mathrm{MPa}$ \\
\hline
\end{tabular}

reinforcement rate of stirrups is $0.45 \%$. The upper incision is a regular trapezoidal and was opened at $110 \mathrm{~m}$, the incision central angle is $210^{\circ}$, the incision height is $2.5 \mathrm{~m}$, and the angle of the directional window is $45^{\circ}$. The lower incision is a regular trapezoid and was opened at the bottom of the chimney, the incision central angle is $216^{\circ}$, the incision height is $3.5 \mathrm{~m}$, and the angle of the directional window is $45^{\circ}$. The upper incision detonates $3 \mathrm{~s}$ before the lower incision.

The reinforced concrete chimney finite element equivalent model is shown in Figure 12. The model of the chimney is constituted of three parts: the upper blasting incision, the lower blasting incision, and the equivalent reinforced concrete cylinder. The equivalent reinforced concrete cylinder adopts the proposed material, and the Solid164 element is used to build the model. The ground adopts the SOLID164 element and rigid body model, the rigid body density is $2000 \mathrm{~kg} / \mathrm{m}^{3}$, the elastic modulus is $30 \mathrm{GPa}$, and Poisson's ratio is 0.2 . Gravity is achieved through * LOAD_BODY_Y. The contact between the cylinder and ground is defined through *CONTACT_ERODING_SINGLE_SURFACE. The blasting incision is realized by the time control parameter through *MAT_ADD_EROSION. The elements in the blasting 


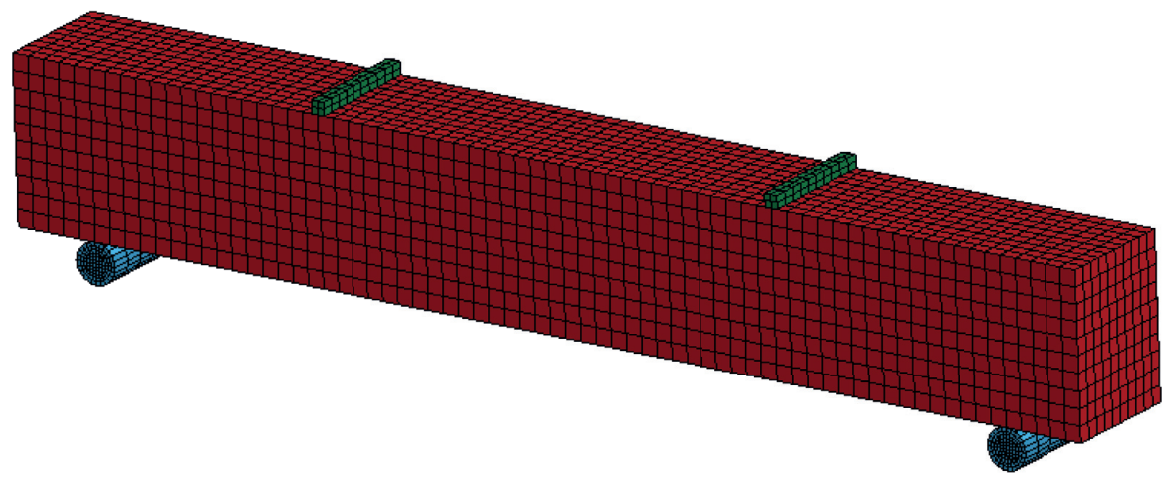

FIGURE 10: Finite element model of the simplified reinforced concrete simply supported beam.

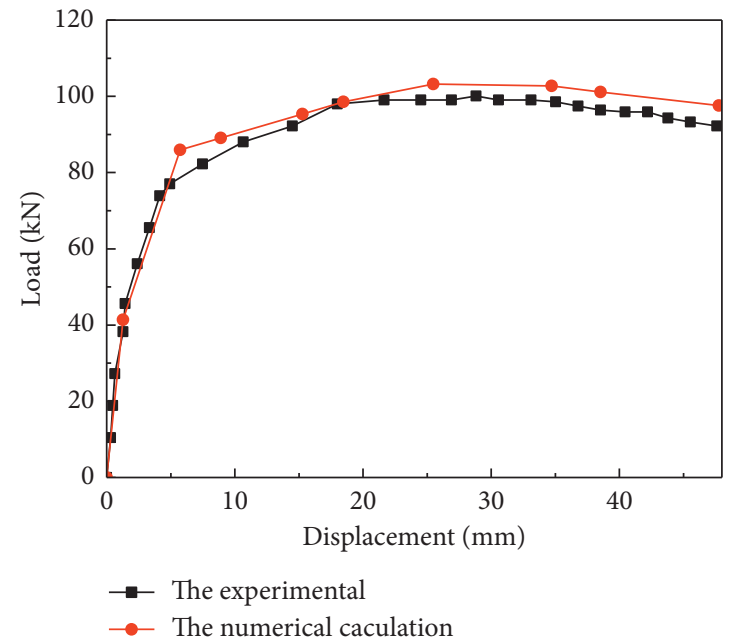

FIGURE 11: Comparison of the load-displacement curve between numerical calculation and experimental result of the reinforced concrete simply supported beam simplified model.

incision are deleted by one-time control, without considering the impact of the explosive explosion on the formation of the incision. The parameters of the equivalent reinforced concrete cylinder are shown in Table 4.

Bringing the above parameters into the numerical model, the numerical calculation result and the experimental result of chimney blasting demolition can be obtained in Figure 13.

By controlling the detonation time of the upper incision and the lower incision of the model, making the initiation time of the model incision is the same as that of the actual incision. It can be seen from Figure 13 that the measured collapse process of the chimney is the same as the numerical calculation result before the 4th second. After the 4th second, the upper structure of the numerical model shifted slightly to the right compared with the actual collapse of the chimney, which was caused by the unevenness of the chimney material and weathering. However, on the whole, the measured collapse process of the chimney has a high degree of consistency with the numerical calculation result. The user-defined function of the simplified model allows users to perform equivalent processing of complex materials. On the premise of ensuring accuracy, the computational efficiency has increased by $30 \%$ and $35 \%$, respectively, compared with the HJC model and the RHT model. At the same time, the correctness and 


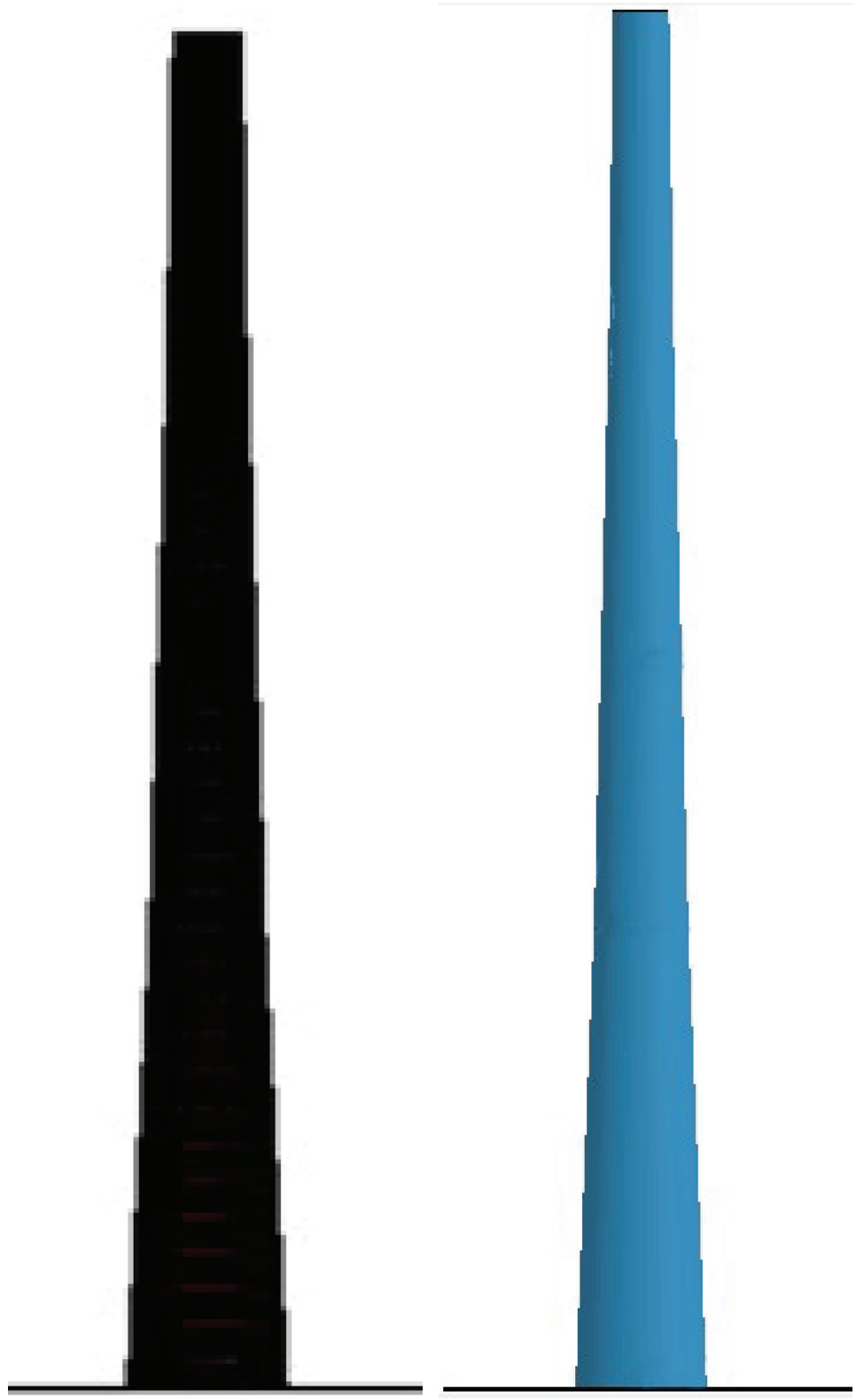

FIGURE 12: Finite element model of reinforced concrete chimney.

TABLE 4: Simplified model parameters of reinforced concrete chimney.

\begin{tabular}{lr}
\hline The strain & The stress \\
\hline$\varepsilon_{c, 1}=1.2 \times 10^{-3}$ & $\sigma_{c, 1}=11.41 \mathrm{MPa}$ \\
$\varepsilon_{c, 2}=4.5 \times 10^{-3}$ & $\sigma_{c, 2}=39.72 \mathrm{MPa}$ \\
$\varepsilon_{c, 3}=4.7 \times 10^{-3}$ & $\sigma_{c, 3}=39.01 \mathrm{MPa}$ \\
$\varepsilon_{t, 1}=1.4 \times 10^{-5}$ & $\sigma_{t, 1}=4.80 \mathrm{MPa}$ \\
$\varepsilon_{t, 2}=1.2 \times 10^{-3}$ & $\sigma_{t, 2}=1.80 \mathrm{MPa}$ \\
\hline
\end{tabular}



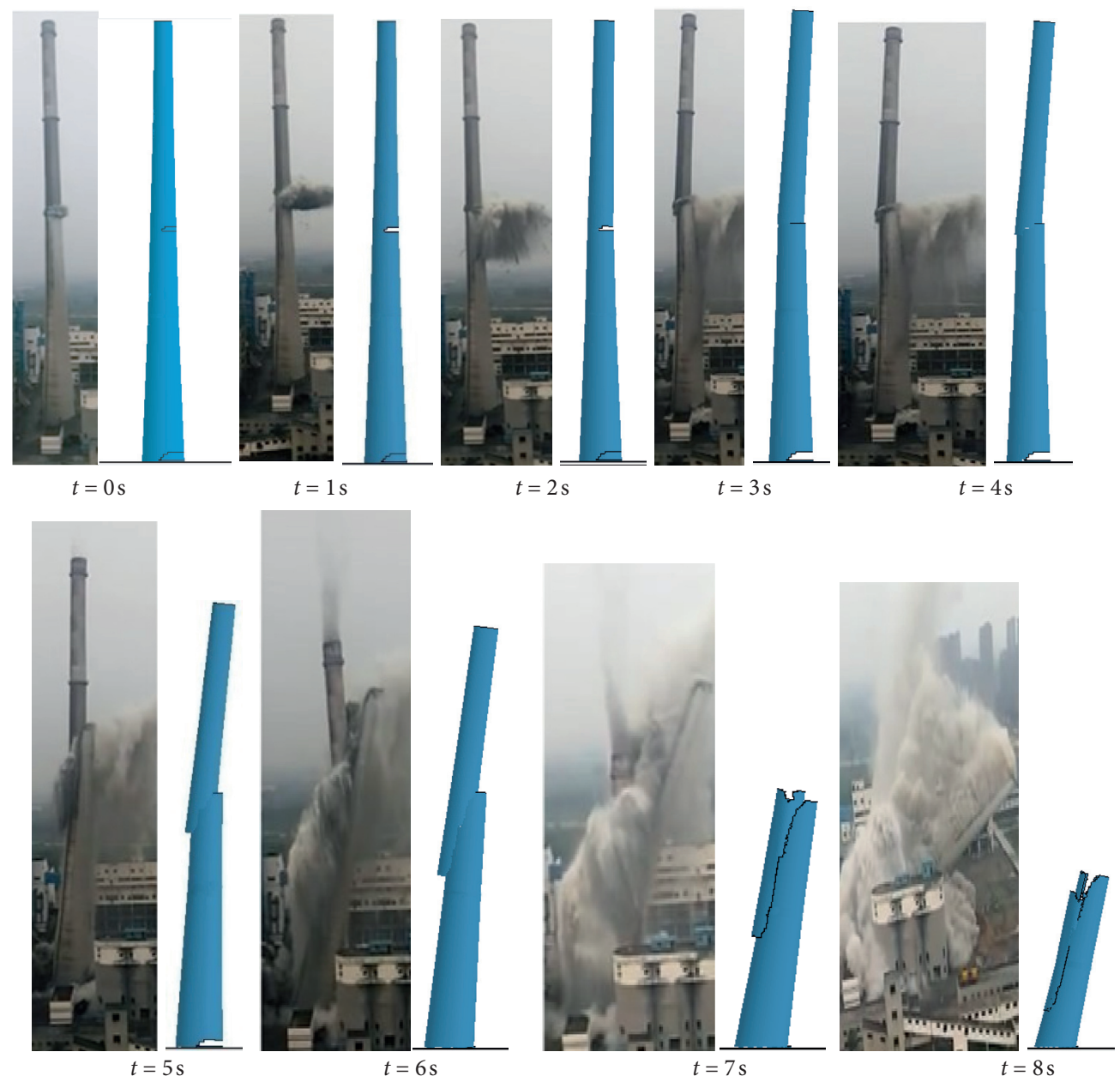

FIGURE 13: Comparison between numerical simulation and actual collapse process of chimney blasting demolition.

rationality of the selection of the parameters of the simplified model are also verified.

\section{Conclusion}

(1) The simplified reinforced concrete model illustrated in this paper can not only reflect the softening behavior characteristics of concrete but also reflect the characteristics of concrete material tensile stress truncation. On the premise of ensuring the calculation accuracy, the modeling workload is greatly simplified.

(2) The simplified model has the function of self-defining compression and tension parameters, which can accurately reflect the constitutive relationship of the reinforced concrete model, and greatly improves the efficiency of finite element calculation.

(3) Demolition blasting is nonrepeatable and highly dangerous, and the effect of numerical calculation as an effective analysis method is becoming more and more obvious. The numerical calculation result of the simplified reinforced concrete model used in this paper is highly consistent with the actual high-speed photographic observation result. Therefore, the numerical calculation technique can provide a reference for similar blasting demolition projects.

\section{Data Availability}

The numerical data used to support the findings of this study are available from the corresponding author upon request.

\section{Conflicts of Interest}

The authors declare that there are no conflicts of interest regarding the publication of this article.

\section{Acknowledgments}

This work was supported by the National Science Foundation of China (grant nos. 50474040 and 50674078) and the National High Technology Research and Development Program of China (grant no. 2012AA061201).

\section{References}

[1] S. Wei and Y. Yong, "Damage constitutive law of reinforced concrete specimens under monotonic uniaxial tensile load," Engineering Mechanics, vol. 45, no. 8, pp. 142-147, 2015. 
[2] O. Bifeng and W. Junjie, "A Microplane dynamic model for reinforced concrete," Journal of Vibration and Shock, vol. 26, no. 12, pp. 74-80, 2007.

[3] S. Lin, J. Ning, and Y. Sun, "The constitutive relationship of reinforced concrete subjected to shock loading," Acta Mechanica Solida Sinica, vol. 26, no. 2, pp. 175-181, 2005.

[4] S. Xinjin, W. Chenyuan, and Z. Lin, "A Damage Plastic Constitutive Model for Reinforced Concrete and its Engineering application," Engineering Mechanics, vol. 24, no. 9, pp. 122-128, 2007.

[5] D. Kong, J. Zhao, and P. Wang, "Finite element analysis of reinforced concrete materials Equivalent modulus method," Journal of Shenyang Jianzhu University, vol. 121, no. 13, pp. 200-203, 2005.

[6] P. Chao, L. Zhu, T. Yunfang et al., "Revised plasticity damage constitutive model of reinforced concrete equivalent material and its application in seismic analysis," Building Structure, vol. 45, no. 8, pp. 19-24, 2015.

[7] LS-DYNA, Keyword User's Manual Volume II Material Models. LS-DYNAR7.1, Liver More Software Technology Corporation (LSCT), Troy, MI, USA, 2016.

[8] National Standard of the People's Republic of China, GB50010-2010 Code for Design of Concrete Structures, China Building Industry Press, Beijing, China, 2010.

[9] J. B. Mander, M. J. N. Priestley, and R. Parke, "Observed stress-strain behavior of confined concrete," Journal of Structural Engineering, vol. 114, no. 8, pp. 1827-1849, 1988.

[10] L. Liu, Y. Zhang, L. I. Qian et al., "Study on axial compression performance of $500 \mathrm{MPa}$ reinforced concrete short columns," Journal of Zhengzhou University, vol. 41, no. S2, pp. 1-5, 2006.

[11] S. Xiao, W. Cao, H. Pan et al., "Experimental study on mechanical properties of reinforced concrete beams under different loading rates," Journal of Building Structures, vol. 33, no. 12, pp. 142-146, 2012.

[12] P. Xu, D. Liu, and Y. Zhang, "A new damage plasticity model for reinforced concrete," Explosion and Shock Waves, vol. 38, no. 5, pp. 977-984, 2018. 